\title{
The 2nd International Conference on Surfaces, Coatings and Nanostructured Materials: Asia (NANOSMAT-Asia, 2015)
}

\author{
Mahmood Aliofkhazraei ${ }^{1} \cdot$ Nasar Ali $^{2} \cdot{\text { Bernd } \text { Michel }^{3}}^{3}$
}

Published online: 12 April 2016

(C) Springer-Verlag Berlin Heidelberg 2016

This special issue of Microsystem Technologies contains papers from the 2nd International Conference on Surfaces, Coatings and Nanostructured Materials-Asia (NANOSMAT-Asia, 2015). For this special issue, high quality papers were accepted for publication after strict peer review. The 2nd International Conference on Surfaces, Coatings and Nanostructured Materials-Asia was held in RADISSON BLU hotel in Kayseri, TURKEY during 24-27 March 2015. NANOSMAT conferences provide a unique platform for discussing key aspects of materialsrelated nanoscience and nanotechnology and their different applications. We would like to thank all the delegates for their interest and efforts in making NANOSMAT-Asia conferences a success every time. We are thankful to all our invited speakers for accepting our invitations and offering to share their knowledge with the NANOSMAT delegates.

We would like to express our acknowledgements to all the authors and reviewers, with a special thanks to the Microsystem Technologies for accepting publication of this special section. We hope that this issue is fruitful in terms of scientific exchange, and that it will contribute to strengthening the existing science and shaping the field of nanotechnology.

The 3rd NANOSMAT-Asia conference will be held in 2017 possibly in Singapore or Hong Kong (keep checking http://www.nanosmat.co.uk for latest updates). It is

Mahmood Aliofkhazraei

maliofkhazraei@gmail.com

Tarbiat Modares University, Tehran, Iran

The NANOSMAT Society, Manchester, UK

3 Micro Materials Center, Microsystem Technologies, Berlin, Germany expected that the best papers presented at the conference will be published in the Microsystem Technologies. We encourage you to submit your high quality papers to our next special issue in 2017. See you again in the NANOSMAT-Asia 2017 conference.

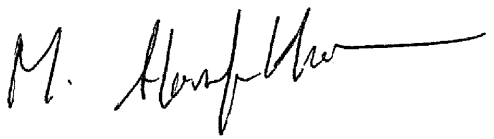

Prof. Mahmood Aliofkhazraei

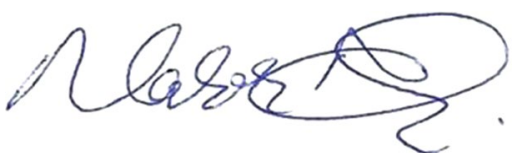

Prof. Nasar Ali<smiles>[As]</smiles>

Prof. Bernd Michel,

Editor-in-Chief.

Microsystem Technologies 